\title{
Preterm Births among Women with Short Birth Interval in Two Hospitals in Baghdad / Al-Karkh
}

\author{
Nibras A. Hussain FIBMS/FM, Atheer J. Al-Saffar FIBMS/CM \\ Family and Community Medicine, College of Medicine, Al-Nahrain University, Iraq
}

\begin{abstract}
Background The World Health Organization had recommended that individuals and couples should wait for at least (2-3) years between births in order to reduce the risk of adverse maternal and child health outcomes.

Objective The current study was an attempt to measure the rate of preterm births among women with interbirth intervals of less than three years. It also attempted to describe some socio-demographic characteristics of these women with short intervals.

Methods A cross-sectional study was conducted in two hospitals at Baghdad / Al-Karkh district with a total 360 women were interviewed at the delivery room using a questionnaire specially prepared for this purpose during the period from the $1^{\text {st }}$ of April to the $31^{\text {st }}$ of May 2009.

Results The mean interbirth interval for the sample was $20.4 \pm 6.43$ months gave a rate of preterm births of $17.8 \%$ with a significant association between short intervals and high occurrence of preterm births. It was found that women with short interbirth intervals were mostly of younger age, housewives, low educated, not using contraceptives, had a female baby in the last delivery before the current one and their monthly income was 500000 Iraqi dinars or less ( about 385 USD).

Conclusions The rate of preterm births in women with short birth intervals less than three years was relatively high and significantly associated with short birth intervals.

Key words Preterm births, Short birth interval, Socio-demographic characteristics
\end{abstract}

List of abbreviation: WHO = World Health Organization, USAID $=$ United States Agency for International Development, UNICEF = United Nations International Children's Emergency Fund, USA = United States of America, DHS = Demographic and Health Surveys

\section{Introduction}

$\mathrm{B}$ irth spacing is the practice of timing the period between births ${ }^{(1)}$, while birth interval is the period between two consecutive live births, from birth date of a child to birth date of the other ${ }^{(2)}$. Preterm birth is defined as gestational age at birth of less than 37 completed gestational weeks ${ }^{(3)}$. The World Health Organization (WHO) and other International Organizations recommended that individuals and couples should wait for at least (2-3 years) between births in order to reduce the risk of adverse maternal and child health outcomes. Recent studies supported by USAID, UNICEF and others suggested that interval of (3-5 years) might help to reduce these risks ${ }^{(4)}$. Children born close together have long been associated with an increased risk of adverse health outcomes, including increased perinatal, infant, child and maternal morbidity and mortality ${ }^{(5,6)}$. Preterm birth is one of the risks of perinatal outcomes, and it is the single most important cause of perinatal mortality in North America and Europe ${ }^{(7,8)}$, also it is responsible for nearly half of all cases of congenital neurological disabilities, including cerebral palsy, in addition, there was increased risk of 
breathing, immune system, vision and hearing problems $^{(9)}$.

Regarding mother health a comparison of mothers with less than (15) months birth intervals with those of (27-32) months birth intervals revealed that there are increased risk of maternal death, third trimester bleeding in pregnancy, premature rupture of membrane, anemia and puerperal endometritis ${ }^{(10,11)}$.

A variety of demographic and socioeconomic characteristics influences women's spacing practices including younger age ${ }^{(1)}$, no or less educated ${ }^{(12)}$, unemployment ${ }^{(13)}$, and living in rural areas were more likely to have birth intervals shorter than three years ${ }^{(1)}$.

In Iraq, a study was conducted in Mosul, in the north of Iraq in 2004 found a significant association between preterm birth and women who conceived at shorter birth interval ${ }^{(14)}$.

The current study aimed to measure the rate of preterm births among women with interbirth intervals of less than three years. It also attempted to describe some sociodemographic characteristics of these women with short intervals

\section{Methods}

A cross-sectional study was conducted on 360 ladies with birth intervals less than three years, attending the delivery rooms of Al-Imamein AlKadhimein Medical City and Al-Shaheed AlHakeem General Hospital in Al-Shoulaa, at AlKarkh district in Baghdad, from the $1^{\text {st }}$ of April 2009 to the end of May 2009. A consecutive sample of all the women who fulfilled the inclusion criteria were included in the study and those were; women at age (18-45) years, had birth interval of less than 3-years during her current pregnancy, and with singleton pregnancy. Women with hypertension, diabetes, smokers, had any congenital abnormalities in the current delivered baby and her previous pregnancy before the current one ended with abortion were excluded from the study. A questionnaire included demographic information of the mother as age, occupation, residence, years of education, and monthly income was used. Also obstetrical data related to date of last menstrual period, using of contraception before this pregnancy, number and sex of the previous lived children and date of birth of the last child before the current pregnancy. The confirmation of gestational age was done by estimation of expected date of delivery, ultrasound report at first trimester and obstetrician / pediatrician notes.

Statistical analysis was done using SPSS (statistical package for social sciences) version (16) computer software. A level of significance of less than 0.05 was considered as statistically significant.

\section{Results}

The mean interbirth interval for all the participants was $(20.4 \pm 6.43)$ months with a range of (9-35) months. The mean age of the women who participated in the study was $(27.6 \pm 6.5)$ years with $81.7 \%$ of them were 34 years old and younger, about $63.6 \%$ of the women had education of less than secondary school level. The mean gestational age for the delivered infants of the whole sample was $(38.2 \pm 2.5)$ weeks with a range of (26-41) weeks (Table 1). Most of the ladies (82.2\%) included in the study were unemployed, (91.7\%) of them lived in urban areas, and more than two thirds of them were not using contraception before conceiving the current pregnancy. More than half $(55.6 \%)$ of the women had a female sex baby in the last birth order before the current pregnancy, and about three quarters of the sample (76.1\%) had income less or equal to 500000 Iraqi Dinars per month (385 USD) in spite of it ranged from 50000 to 2250000 Iraqi Dinars per month (Table 2).

Among this sample 64 women (17.8\%) gave preterm labor, and the remaining 296 (82.2\%) gave full term labor (Figure 1).

There were no significant difference found regarding the mean age, years of education and income of mothers for both groups $(\mathrm{P}=0.895, \mathrm{P}=0.6$ and $\mathrm{P}=0.72$ ) respectively (Table 3). 
Also regarding mother occupation, the use of contraception, and the sex of the last baby before the current pregnancy there were no significant difference between term and preterm birth. ( $\mathrm{P}=0.34, \mathrm{P}=0.12$ and $\mathrm{P}=0.07)$ respectively, however, there was a significant association between the preterm deliveries and living in rural areas $\mathrm{P}=0.005$ (Table 2).
Comparing women who had preterm with those with term deliveries; there was significant difference in the mean interbirth interval between them $(18.8 \pm 5.43$ versus $20.7 \pm 6.58$ months respectively, $\mathrm{P}=0.03$ ) (Table 4).

Table 1. Distribution of the sample according to some continuous demographic variables

\begin{tabular}{cccc}
\hline Variables & Mean & SD & Range \\
\hline Age of mother (years) & 27.6 & 6.46 & $(18-45)$ \\
Education of mother (years) & 8.75 & 4.48 & $(0-18)$ \\
Income per month (ID) & 421670 & 262807 & $(50000-2250000)$ \\
Gestational age (weeks) & 38.2 & 2.52 & $(26-41)$ \\
Interbirth interval (months) & 20.4 & 6.43 & $(9-35)$ \\
\hline
\end{tabular}

Table 2. Relation between preterm and term birth regarding mother occupation, residence, the use of contraception and the sex of the last baby before the current delivery and their distribution percent

\begin{tabular}{|c|c|c|c|c|c|}
\hline \multicolumn{2}{|c|}{ Variable } & $\begin{array}{c}\text { Preterm } \\
\text { Number (\%) }\end{array}$ & $\begin{array}{c}\text { Term } \\
\text { Number (\%) }\end{array}$ & $\begin{array}{c}\text { Total } \\
\text { Number (\%) }\end{array}$ & Significance \\
\hline \multirow{2}{*}{ Occupation } & Unemployed & 50 (16.9\%) & 246 (83.1\%) & $296(100 \%)$ & $X^{2}=0.894$ \\
\hline & Employed & $14(21.9 \%)$ & $50(78.1 \%)$ & 64 (100\%) & $P=0.34$ \\
\hline \multirow{2}{*}{ Residence } & Urban & 53 (16.1\%) & 277 (83.9\%) & 330 (100\%) & $X^{2}=7.988$ \\
\hline & Rural & $11(36.7 \%)$ & $19(63.3 \%)$ & $30(100 \%)$ & $P=0.005$ \\
\hline \multirow{2}{*}{$\begin{array}{c}\text { Contraception } \\
\text { use }\end{array}$} & Used & $10(12 \%)$ & $73(88 \%)$ & $83(100 \%)$ & $X^{2}=2.423$ \\
\hline & Not used & 54 (19.5\%) & $223(80.5 \%)$ & 277 (100\%) & $P=0.12$ \\
\hline \multirow{2}{*}{ Sex of last baby } & Male & $20(12.5 \%) 42$ & 140 (87.5\%) & $160(100 \%)$ & $X^{2}=3.29$ \\
\hline & Female & $(21 \%)$ & $158(79 \%)$ & 200 (100\%) & $P=0.07$ \\
\hline
\end{tabular}

Table 3. Significant association regarding age, years of education and income of mothers between preterm and term births

\begin{tabular}{cccc}
\hline Mother variables & $\begin{array}{c}\text { Preterm } \\
\text { Mean }( \pm \text { SD) }\end{array}$ & $\begin{array}{c}\text { Term } \\
\text { Mean }( \pm S D)\end{array}$ & Significance \\
\hline Age (years) & $27.5( \pm 6.47)$ & $27.6( \pm 6.46)$ & $\begin{array}{c}\mathrm{t} \text {-test }=0.132 \\
\mathrm{P}=0.895 \\
\mathrm{t} \text {-test }=0.497 \\
\mathrm{P}=0.6\end{array}$ \\
$\begin{array}{c}\text { Education (years) } \\
\begin{array}{c}\text { Income in ID per } \\
\text { month }\end{array}\end{array}$ & $8.5( \pm 4.79)$ & $8.8( \pm 4.42)$ & $\mathrm{t}$-test $=0.360$ \\
$\mathrm{P}=0.72$
\end{tabular}


Table 4. The mean interbirth interval of women with term and preterm deliveries

\begin{tabular}{cccc}
\hline Interbirth interval & $\begin{array}{c}\text { Preterm } \\
\text { Mean }( \pm S D)\end{array}$ & $\begin{array}{c}\text { Term } \\
\text { Mean }( \pm S D)\end{array}$ & Significance \\
\hline Interbirth interval (months) & $18.8( \pm 5.43)$ & $20.7( \pm 6.58)$ & t-test $=2.209$ \\
$P=0.028$
\end{tabular}

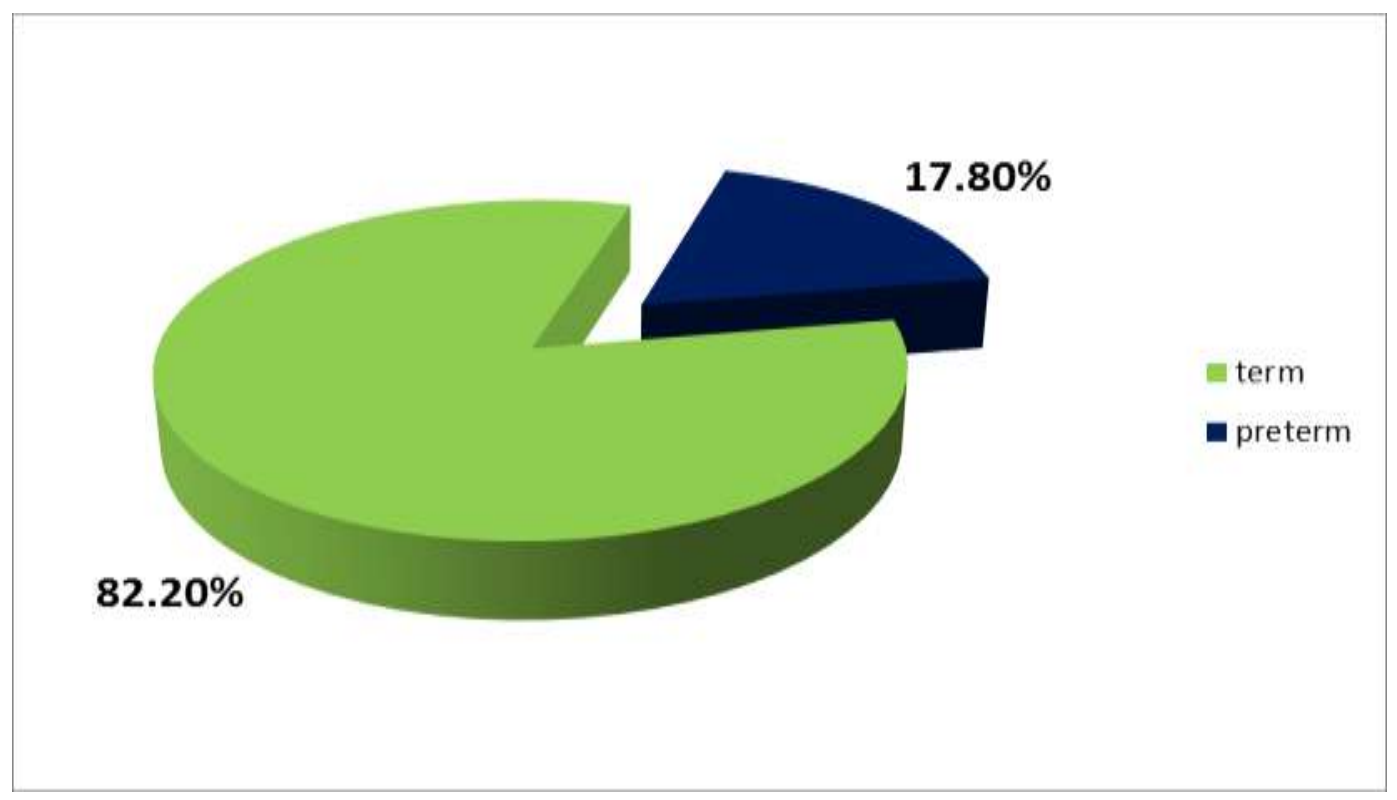

Fig. 1. The rate of preterm birth among the sample

\section{Discussion}

Several studies have shown that women with short interval pregnancies are at increased risk of complications and preterm birth was one of these complications (6,15,16). The largest proportion of women with short birth intervals of less than three years were reported from the developing countries of the Middle East region, such as Jordan and Yemen, as well as from Turkmenistanin Central Asia ${ }^{(1)}$. While in Iraq, the problem of prematurity is becoming an ever growing one (17), no previous published researches tried to identify the rate of preterm birth in short interbirth intervals.

The rate of preterm birth in this sample of women with short interbirth intervals was $(17.8 \%)$, and this is higher than general preterm birth rates recorded in developed and many developing countries as well as more than preterm deliveries in general population of Iraq $(6.5 \%)^{(18)}$.

The United States National Center for Health Statistic reported that preterm birth rates in USA is $(12.7 \%)^{(19)}$. This study found that the mean birth interval of women with preterm deliveries was significantly less than those with term deliveries, and this is similar to many previous studies like studies done on Emirati women in 2002 and in Gaza strip in 2007 which found increase occurrence of preterm birth with short interbirth intervals duration ${ }^{(1,6,20,21)}$. In this research, it was also found that the women with short birth intervals were mostly young of 34 years or less, housewives, and of low educational level "not reach the secondary school", these findings are similarly reported by many countries like Egypt, Jordan and Turkey through the DHS data ${ }^{(1)}$. Although most of the women included in this study lived in urban 
areas, but the study found that there was a significant association between living in rural areas and the occurrence of preterm births and this finding may be attributed partly to shorter interbirth intervals and found in previous other studies $(16,22,23)$. No significant association was found between the age of mother and having preterm births unlike previous studies, which found that both extremes of age less than 18 and more than 45 were associated with increased rates of preterm births ${ }^{(24,25)}$; and this is the reason for selecting the sample with exclusion of very young or old aged women to counteract the confounding effect of age that can contribute for preterm deliveries. Despite there is a known relation between maternal occupation and education with the occurrence of preterm births as preterm births increase in employed women specially with heavy manual work and with illiteracy ${ }^{(22,23)}$, but in this study there was no significant association between occupation and education of mother and the occurrence of preterm births. No significant relation found between the income and the occurrence of preterm births and this was also found in previous studies which found no effect of socioeconomic status of the couples on the rate of preterm births ${ }^{(26)}$, while other studies found the reverse as there was association between the preterm births occurrence and socioeconomic status of the family ${ }^{(27,28)}$.

It can be concluded from this study that the rate of preterm births in women with short birth intervals of less than three years was relatively high and significantly associated with short birth intervals.

\section{Acknowledgment}

To all participants in this study .

\section{Author contributions}

Dr. Atheer J Al-Saffar (Design, Methodology and Manuscript writing), Dr. Nibras Alaa Hussain (protocol preparation, data collection, literature review, and manuscript draft writing).

\section{Conflict of Interest}

The authors have no conflicts of interest.

\section{Funding}

None.

\section{References}

1. Rutstein S. Effect of birth interval on mortality and health: Multivariate cross-country analysis. MACRO international, presentation at USAID, July 2000. In: Setty-Venugopal V, Upadhyay UD. Birth spacing: 3-5 saves lives. Baltimore, Johns Hopkins Bloomberg School of Public Health. Population information program, 2002. (Population reports, series L, NO.13).

(https://www.k4health.org/sites/default/files/l13.pdf).

2. Conde-Agudelo A, Rosas-Bermudez A, Castano $F$, Norton M. Effects of birth spacing on maternal, perinatal, infant, and child health: a systematic review of causal mechanisms. Stud Fam Plann. 2012; 43: 93114.

3. Lumely J. Defining the problem: The epidemiology of preterm birth. BJOG. 2003; 110 (suppl.20): 3-7.

4. WHO: Report of the WHO technical consultation on birth spacing, held in Geneva, Switzerland, on 13-15 June 2005.

(www.who.int/making pregnancy safer/.../birth spaci ng.pdf).

5. Smith GC, Pell JP, Dobbie R. Interpregnancy interval and risk of preterm birth and neonatal death: a retrospective cohort study. British medical journal. 2003; 327 (7410): 313-9.

6. Conde-Agudelo A, Belizan JM, Norton MH, et al. Effect of the interpregnancy interval on perinatal outcomes in Latin America. Obstetric Gynecol. 2005; 106(2): 359-66.

7. Conde-Agudelo A, Rosas-Bermudez A, Kafury-Goeta AC. Birth spacing and risk of adverse perinatal outcomes: a meta-analysis. JAMA. 2006; 295(15): 1809-23.

8. Graafmans WC, Richardus JH, Macfarlane A, et al. Comparability of published perinatal mortality rates in Western Europe; The quantitative impact of difference in gestational age and birth weight criteria. BJOG. 2007; 108: 1237-45.

9. Wang $M L$, Dorer DJ, Fleming $M P$, et al. Clinical outcomes of near-term infants. Pediatrics 2004, 114: 372-6.

10. Conde-Agudelo A, Belizan JM. Maternal morbidity and mortality associated with interpregnancy interval: Cross-sectional study. British medical journal. 2000; 321(7271): 1255-9.

11. Johnson RS, Conde-Agudelo A. Systematic literature review and meta-analysis of the relationship between interbirth intervals and infant and child mortality. Reports submitted to Catalyst Consortium Oct.2004. 
(www.pathfinder.org/.../CATALYST-Fact-Sheet-BirthSpacing.pdf).

12. Choe MK, Thapa S, Achmad S. Early marriage and childbearing in Indonesia and Nepal (East-West Center Working Papers Population Series, No. 108-15). Honolulu, HI: East-West Center. Nov. 2001, 16 http://www.eastwestcenter.org/system/tdf/private/P OPwp10815. pdf?file=1\&type=node\&id=31869 .

13. Brewster K, Rindfuss R. Fertility and women's employment in industrialized nations. Annu Rev Sociol. 2000; 26: 271-96.

14. Al-Dabbagh S, Al-Taee W. Risk factors for preterm births in Iraq: a case-control study. BMC pregnancy and childbirth; 2006; 18: 6: 13. DOI: 10.1186/1471-2393-613.

15. Fuentes-Afflick E, Hessol NA. Interpregnancy interval and the risk of premature infants. Obstet. Gynecol. 2000; 95: 383-90.

16. Zhu BP, Haines KM, Le T, et al. Effect of the interval between pregnancies on perinatal outcomes among white and black women. AM J Obestet Gynecol. 2001; 185: 1403-10.

17. Nasheit NA. Perinatal and neonatal mortality and morbidity in Iraq. J Mater-Fetal Neonat Med. 2003; 13(1): 64-7.

18. Blencowe $H$, Cousens $S$, Mikkel $Z$, et al. The global action report on preterm birth; data from national, regional and worldwide estimates of preterm birth rates in the year 2010.

(www.who.int/pmnch/media/news/2012/preterm_birt h_report/en/index.html)

19. Martin JA, Hamilton BE, Sutton PD, et al. Births: final data for 2004 national vital statistics report, national center for health statistics. 2006, 55 (1). (www.cdc.gov/nchs/data/nvsr/nvsr55/nvsr55_01.pdf)

20. AbuHamad Kh, Abed Y, AbuHamad B. Risk factors associated with preterm birth in the Gaza strip: hospital-based, case-control. Eastern Mediterranean Health Journal, 2007; 13(5): 1132-41.

21. Al-Jasmi F, Al-Mansoor F, AL-Sheiba A, et al. Effect of inter-pregnancy interval on risk of spontaneous preterm birth in Emirati women, United Arab Emirates. Bulletin of WHO. 2002; 80: 871-5.

22. Muggah $E$, Way $D$, Muirhead $M$, et al. Preterm delivery among Inuit women in the Baffin region of the Canadian Arctic. Int J Circumpolar Health. 2004; 63: 242-7.

23. Ezechi OC, Makinde ON, Kalu BE, et al. Risk factors for preterm delivery in southwestern Nigeria. J Obestet. Gynecol. 2004; 23: 387-91.

24. Jacobsson B, Ladfors L, Milsom I. Advanced maternal age and adverse prenatal outcome. Obstet Gynecol; 2004,104: 727-33.

25. Da Silva AA, Simoes VM, Barbieri MA, et al. Young maternal age and preterm birth, Pediatric perinatal epidemiol. 2003; 17(4): 332-9.

26. Basso O, Olsen J, Christensen K. Low birth weight and prematurity in relation to paternal factors. Int J Epidemiol. 1999; 28: 695-700.

27. Basso O, Olsen J, Christensen K. Study of environmental, social, and paternal factors in the preterm delivery using sibs and half sibs. A populationbased study in Denmark. Epidemiol Comm Health. 1999; 53: 20-3.

28. Kramer M, Seguin S, Lyden, J, et al. Socio-economic disparities in pregnancy outcomes. Pediat Perinatal Epidemiol. 2000; 14: 194-210.

\footnotetext{
Correspondence to Nibras A. Hussain E-mail: nibrasfamily@yahoo.com Received $22^{\text {nd }}$ Dec. 2015: Accepted $14^{\text {th }}$ Aug. 2016
} 